\title{
Aprendizagem baseada em problemas: o mito e a realidade
}

\section{Learning based on problems: mith and reality}

João Ozório R. Neto ${ }^{1}$

Artigo

Cleize Silveira Cunha ${ }^{2}$

Original

Cristiane Silveira Cunha ${ }^{1}$

Adriana Novaes Rodrigues ${ }^{1}$

Original

Mauro Tavares ${ }^{3}$

Paper

Palavras-chave:

Métodos

Educação médica

Aprendizado

\section{Resumo}

Os autores avaliam de forma crítica, aspectos da chegada ao Brasil deste novo método de ensino nas escolas médicas. Comentam aspectos relacionados à sua implantação e analisam os resultados disponíveis na literatura sobre as avaliações do processo de ensino e das reais qualidades desta nova metodologia.

\section{Abstract}

The authors analyze aspects of this new method of teaching at medical schools in Brazil. They discuss the aspects related to its implementation and analyze the results available in literature about the evaluation of the learning process and the real qualities of this new method.
Key words:

Methods

Medical education

Learning

\footnotetext{
' Professor MsC (Ciências da Saúde - UniFOA)

2 Professora Esp. (Ciências da Saúde - UniFOA)

${ }^{3}$ Professor PhD. (Ciências da Saúde - UniFOA)
}

Recebido em 09/2010

Aprovado em 08/2011

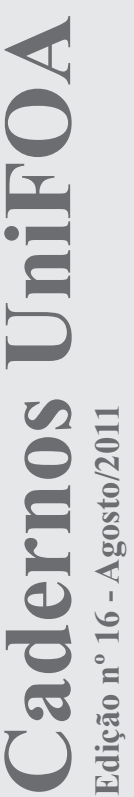




\section{Introdução}

A aprendizagem baseada em problemas (APB) é um dos mais bem descritos métodos de aprendizagem interativa e muitos acham até que é mais eficaz que o método tradicional de ensino da medicina em termos de habilidades de aprendizagem em longo prazo, além do mais, é mais divertida. (SMITS, 2002).

Esse método revolucionário de ensino foi criado na década de 60 pelo Professor Howard Barrows para a Universidade MacMaster, Ontário, Canadá. Ele fundamenta todo o aprendizado, inclusive o das ciências básicas, na discussão de casos clínicos de papel, como forma de motivar e mobilizar o aluno para a solução de problemas reais. Barrows admitiu que sua maior motivação para desenvolver a ABP foi o ínfimo aproveitamento verificado por ele, entre seus alunos, nas disciplinas do curso básico de graduação em Medicina do currículo tradicional. Atribuiu esta constatação, não a incompetência dos docentes do curso básico, mas, principalmente, a falha do método de ensino. (VOLTARELLI, 1998).

No contexto da Escola Médica, a ABP ainda é uma ação de contracultura, na medida em que se traduz em uma forma de aprendizagem ativa que procura compreender os princípios e os processos dos fenômenos investigados e que, portanto, estimula o interesse pela investigação.

A ABP pressupõe a cooperação em pequenos grupos, condução por um tutor, estudo autodirigido, educação multidisciplinar e avaliações progressivas. (BARROS, 2006).

No Brasil, no início dos anos 90, as Faculdades de Medicina de Londrina e Marília adotaram uma nova proposta curricular para a Educação Médica, sob a tutela da Fundação Kellog. Essa proposta adotava a ABP com uma orientação para a medicina comunitária conhecida como Educação Baseada na Comunidade (em inglês - Community Based Education). Fundamentava-se em documento da Organização Mundial de Saúde conhecido como: "Changing Medical Education: an agenda for action". Esse documento conclamava a adaptação do ensino médico às novas exigências, indicando como o principal motivo de insatisfação da sociedade em relação aos médicos e a outros profissionais de saúde, sua incompetência para enfrentar os novos desafios: Humanização da atenção, cuidados integrados, maior penetração social, equidade, contenção de custos, uso inadequado da tecnologia, proteção do meio ambiente e promoção do estilo de vida mais saudável (FEUERWERKER, 2002).

Na visão de FLEXNER (1910), o currículo médico tradicional deveria ser dividido em duas partes (básico e clínico) e ser conduzido no laboratório e no hospital (RAW, 2007). Embora fosse um modelo pedagógico proposto para eliminar a passividade do aluno por meio de métodos ativos de aprendizagem, a lógica fazia supor que, na prática, desapareceriam os elementos autoritários considerados intrínsecos à didática. Porém, ao final de um século de experiência com métodos nominalmente ativos, verifica-se que foram adotados para ostentar uma pretensa modernidade (SALGADO,1997).

A ABP foi estruturada para romper com esses modelos ultrapassados. Mais de uma década após a implementação da ABP nos Estados Unidos da América e em outros países do mundo, o debate sobre seus méritos ainda persiste. Porque a ABP falhou em cumprir as suas promessas e expectativas? (GLEW, 2003). Existiriam outros fatores envolvidos na disseminação de um modelo de ensino, criado em um país desenvolvido, com uma escola médica totalmente diferente daquelas dos países em desenvolvimento?

Assim, o presente artigo se propõe a discutir e refletir sobre os fatores que procurariam explicar tais questões.

\section{Metodologia}

Através da busca, seleção e avaliação sistemática da literatura sobre a ABP, além de sua origem e consequências, pretende-se avaliar suas transformações e sua chegada aos países em desenvolvimento, com a finalidade de emitir juízo de valor sobre essa nova metodologia de ensino.

\section{Discussão}

A busca, a seleção, a avaliação crítica e a aquisição de conhecimento visando a uma aplicação prática ou a uma reflexão consti- 
tuem um processo ao longo da vida do indivíduo (KOMATSU, 1998). Quando em alguma época as opções disponíveis são escassas não se precisa desenvolver capacidade de escolha; na verdade não há muito a escolher. Na medida em que se tem mais de uma opção exige-se a capacidade de distinguir a mais adequada. (PORTO, 1987).

A evolução do conhecimento é muito rápida e não uniforme. No campo da ciência, a verdade, pelo seu caráter transitório, é permanentemente posta à prova graças à aquisição de novos conhecimentos. Embora hoje se tenha a sensação de envelhecimento precoce dos objetos, aparelhos, máquinas e até mesmo das ideias, uma observação adequada permite distinguir ocorrências paradoxais e desdobramentos decorrentes do próprio progresso. (MORAES, 2007).

Uma análise pouco passional da criação da ABP indica que o objetivo principal era econômico. A supressão do ciclo básico e a justificativa da incorporação das disciplinas básicas no ciclo clínico para a solução de problemas de papel é no mínimo inquietante. Esse modelo serviria a escolas que almejariam grandes lucros com grandes reduções de despesa pela diminuição do corpo docente. Seu aparecimento coincide com um aumento maciço no número de matrículas na educação superior, no hemisfério Norte do pós-guerra devido a uma dinâmica de democratização do ensino secundário norte-americano graças ao desenvolvimento do sistema público de ensino superior e universitário.

Uma população importante e diversificada teve acesso a estudos superiores. No decorrer das décadas seguintes, sob pressão das novas políticas governamentais de ajuda aos estudantes sem dinheiro, do movimento dos direitos civis dos negros e das lutas feministas, as instituições privadas tiveram que fazer coexistirem os que eram socialmente bem colocados e os que eram escolarmente bem preparados. Com a multiplicação dos estabelecimentos públicos de qualidade e uma escolaridade a baixo custo, o aparecimento de bolsistas nas universidades fortaleceu a ideia de um ensino superior aberto a (quase) todos, bastava trabalhar muito. (FANTASIA, 2004).

Entre 1940 e 1970 as matrículas na universidade americana multiplicaram-se por cinco, evoluindo de 1,5 milhão para quase 8,0 milhões.Nos 30 anos seguintes, as inscrições dobrariam outra vez. (NEWFIELD, 2007) Harvard introduziu a ABP através de Alexander Leaf que justificava sua implantação como auxílio para desenvolver a educação continuada baseada na curiosidade aumentando a automotivação dos estudantes.

Ao contrário do esperado, os estudantes desse novo currículo tornaram-se muito mais passivos, aceitando tudo o que lhes era dito de forma autoritária, nunca questionando a forma de dizer (GOLDHABER, 1973). Segundo esse mesmo autor, após seis anos de utilização, Harvard retornou ao currículo tradicional. $\mathrm{O}$ fator decisivo para o retorno foi o péssimo desempenho dos alunos nos exames do National Board. Sempre acostumada aos primeiros lugares, Harvard ficou em terceiro lugar na classificação geral e em relação às cadeiras básicas ficou em $15^{\circ} \mathrm{em}$ farmacologia e $10^{\circ}$ lugar em patologia; algo nunca antes pensado. Coincidentemente, nesta mesma época, foi proposta pelo governo militar instituído após o golpe de 1964, no Brasil, uma proposta de reforma curricular para a universidade brasileira, incluindo o ensino médico.

A reforma de 1968 aboliu o sistema de cátedra e ainda que a participação política em nossas universidades estivesse sempre presente, ela não conduziria a polarizações partidárias insuperáveis, sendo possível evitar os problemas da admissão em massa de estudantes sem um mínimo de qualificação. Houve uma explosão de matrículas entre 1965 e 1980 - de 150 mil para 1,5 milhão de estudantes em 15 anos. (SCHAWARTZMAN, 1988).

O golpe militar de 1964 foi o resultado da contradição entre o econômico e o político. Contradição entre um processo que pretendia a internacionalização da economia brasileira e a ideologia nacionalista da maioria da classe política. O plano educacional de o governo militar-autoritário foi aumentar a produtividade da escola pública com a adoção de princípios empresariais, acenando com uma tendência privatizadora da educação. (SILVA JUNIOR, 2005).

É nesse panorama do mundo neoliberal, pautado e regido pela economia de mercado, que surge a ABP como nova metodologia de ensino médico. No Brasil, a implementação da 
nova proposta pedagógica implicou em grande esforço de mobilização. O nível necessário de apropriação em termos conceituais e metodológicos, para construir e efetuar a nova proposta, foi sendo atualizada na prática. Havia clara consciência das limitações existentes sobre a consistência conceitual e as experiências acumuladas.

O grupo coordenador investiu profundamente em capacitação (na sua própria e na dos demais docentes). (FEUERWERKER, 2002). Essa mesma autora relata que o processo de construção do novo currículo foi complexo, configurando novos espaços, novas relações de poder, novos papéis e muitos desafios. Especialmente porque nessa nova construção, nem todas as respostas estão dadas e nem todas as ferramentas disponíveis. Em Harvard, as sessões de reforma curricular foram resolvidas em quartos de motel, nos fins de semana, onde os professores reunidos podiam expor suas ideias e contradições sobre o novo currículo. (GOLDHABER, 1973).

Nas décadas de 80 e 90, a ABP apresentou leves mudanças com um reajuste positivo para se adaptar às novas necessidades dos alunos. (KAUFMAN, 1995). Essa mudança se tornou mais evidente no currículo desenvolvido pela Universidade Maastricht, na Holanda, e o aparecimento do ensino baseado na comunidade (EBC).

Um modelo muito parecido com a EBC foi proposto na reforma universitária dos militares em 1968, conhecido como Integração Docente Assistencial (IDA) cuja expressão máxima foi conseguida no Internato Rural da Universidade Federal de Minas Gerais. A IDA representaria um meio através do qual se poderia gerar uma prática médica que procurasse transformar as condições de saúde da população, implicando na participação da comunidade, não como receptor passivo, mas como um elemento ativo desse processo. Seria, juntamente com a extensão de cobertura da assistência médica do setor público de saúde, uma resposta à crise interna do setor saúde devido à expansão capitalista e ao processo de acumulação de capital pela indústria de equipamentos médicos e pela indústria farmacêutica (INTERNATO RURAL, 2007).

$O$ ensino baseado na comunidade que chegou ao Brasil no início da década de 90 é muito parecido com a proposta da IDA, só que utilizando a $\mathrm{ABP}$ e centrado na comunidade. Assim como a ABP pode ser descrita como arma da estratégia neoliberal para a expansão de escolas médicas que aufeririam grandes lucros através de drásticas reduções do corpo docente e a colocação de cada vez mais médicos no mercado, meros agentes de consumo dos equipamentos e medicamentos produzidos pela indústria detentora das patentes, a $\mathrm{EBC}$ poderia representar, na visão de alguns escritores românticos, a aplicação da pedagogia libertadora de Paulo Freire e uma importante estratégia de inclusão social. Porém seu papel apresenta outra origem.

A forte influência exercida pelo Banco Mundial na política macroeconômica brasileira irradia-se sobre diversos setores, entre eles, a educação. A política educacional desse banco, que se autodenomina: política de cooperação ou de assistência técnica; nada mais representa que uma mera relação comercial, caracterizada por um empréstimo convencional com pesados encargos, rigidez de regras, precondições financeiras e cláusulas inerentes ao financiamento comercial da educação. Os créditos concedidos por essa instituição à educação são parte de projetos econômicos que integram a dívida externa dos devedores com as grandes corporações multilaterais. A estratégia do banco consiste em garantir a estabilidade econômica de nações em desenvolvimento colocando em foco os gastos sociais e $\mathrm{o}$ ataque à pobreza e, por isso, recomenda aos governos, o fornecimento de serviços básicos aos pobres: Saúde elementar, planejamento familiar, nutrição e educação primária.

A educação é tratada pelo banco como medida compensatória para proteger os pobres e aliviar as tensões sociais. Ela também é necessária para a contenção demográfica $\mathrm{e}$ o aumento da produtividade das populações carentes, gerando mais lucros. O controle da natalidade prepara a população feminina para o planejamento familiar e para a vida produtiva. (ALTMANN, 2002).

Que melhor estratégia para a política neoliberal do banco do que a implantação de um currículo em EBC, centrado na comunidade carente. A presença do aluno da escola médica seria o instrumento de prestação de assistência, provendo a saúde elementar dos pobres, reduzindo e apaziguando os conflitos sociais. 
Essa estratégia curricular serviria não só à retórica neoliberal típica da economia de mercado do mundo globalizado, mas fundamentalmente serviria a governos de cunho populista-eleitoreiro, que são comuns nos países em desenvolvimento; em outras palavras, serviria ao credor e ao devedor.

O Banco Mundial como financiador da Organização das Nações Unidas para a Educação, a Saúde e o Trabalho (UNESCO), órgão responsável pelo planejamento estratégico de ações educacionais, recomendou, através de reuniões de seus filósofos como Edgar Morin, a disseminação da EBC para a Ásia, a África e a América Latina.

Outra perspectiva sombria, que merece reflexão, é uma entrevista do Professor Antonio Carlos Lopes, da Secretaria de Educação Superior do Ministério da Educação, ao jornal eletrônico do Conselho Regional de Medicina do Estado de São Paulo, quando ele explica que no momento existem propostas de abertura de 78 novos cursos de medicina na Secretaria, a maioria, fundamentada na ferramenta ABP. Ele manifesta sua desaprovação a isso e afirma "Querem implantar a ABP no Brasil simplesmente porque não têm professores nem tampouco hospitais de ensino". (LOPES, 2007).

Para finalizar, a única justificativa plausível para a mudança tão radical na grade curricular da escola médica seria a pretensa superioridade do aluno formado em ABP sobre aquele egresso do currículo tradicional. Poucos são os trabalhos randomizados que estabelecem tal relação, os que existem não notaram diferenças marcantes entre os dois tipos de aluno. (BERKSON, 1993; KWIZERA, 2003; CARRERO, 2006).

\section{Conclusão}

Importa uma palavra de cautela na avaliação rápida e superficial do novo, em tempos de mundo globalizado, com imensos interesses econômicos em jogo diariamente. Não é possível vislumbrar a possibilidade de libertação do mercado, nem com as reflexões filosóficas de educadores do terceiro mundo, muito menos com o pensamento romântico de filósofos franceses encarregados de pensar a educação.
Tudo faz parte do mesmo jogo estratégico macroeconômico cuja única finalidade é o lucro financeiro a qualquer custo.

\section{Bibliografia}

1. ALTMANN, H. Influência do Banco Mundial no projeto educacional brasileiro. Educação e Pesquisa São Paulo, 2002; 28(1): 77-89.

2. BARROS, N.F. LOURENÇO, L.C.A. O ensino da saúde coletiva no método ABP: Experiência na faculdade de medicina de Marília.Rev Bras Educ Méd, 2006; 30(3)136-46.

3. BERKSON, L. PBL: have the expectations been met Acad Med,1993; 10:S79-S88.

4. CARRERO, E. et al.Comparison and lecture-based approach and PBL for teaching pré-anaesthetic assessment. Disponível em www.journals.cambridge. org. Acessado em 17/09/07.

5. FACULDADEDEMEDICINADAUFMG. Internato Rural. Histórico, 2007. Disponível em: www.ufmg.br/internatorural \historico. htm. Acessado em 16/09/07.

6. FANTASIA, R. Receita Americana para a reprodução da elite. Le monde diplomatique Brasil, 2004. Disponível em ww.diplo.uol.com.br/imprima1020. Acessado em 09/11/07.

7. FEUERWERKER, L. Além do discurso da mudança na educação médica.São Paulo: Hucitec, 2002.

8. GLEW, R.H. The problem with PBL in medical education. BAMBED, 2003;31(1):52-6.

9. GOLDHABER, S.Z. Harvard reverts to tradition.Science, 1973;181:1027-32.

10. JORNALELETRÔNICODOCREMESP. Entrevista com o professor Antonio Carlos Lopes: Sem preceptor não há residência, 2007; 236-4. Disponível em www. cremesp.com.br. Acesso em 18/09/07. 
Essa estratégia curricular serviria não só à retórica neoliberal típica da economia de mercado do mundo globalizado, mas fundamentalmente serviria a governos de cunho populista-eleitoreiro, que são comuns nos países em desenvolvimento; em outras palavras, serviria ao credor e ao devedor.

O Banco Mundial como financiador da Organização das Nações Unidas para a Educação, a Saúde e o Trabalho (UNESCO), órgão responsável pelo planejamento estratégico de ações educacionais, recomendou, através de reuniões de seus filósofos como Edgar Morin, a disseminação da EBC para a Ásia, a África e a América Latina.

Outra perspectiva sombria, que merece reflexão, é uma entrevista do Professor Antonio Carlos Lopes, da Secretaria de Educação Superior do Ministério da Educação, ao jornal eletrônico do Conselho Regional de Medicina do Estado de São Paulo, quando ele explica que no momento existem propostas de abertura de 78 novos cursos de medicina na Secretaria, a maioria, fundamentada na ferramenta ABP. Ele manifesta sua desaprovação a isso e afirma "Querem implantar a ABP no Brasil simplesmente porque não têm professores nem tampouco hospitais de ensino". (LOPES, 2007).

Para finalizar, a única justificativa plausível para a mudança tão radical na grade curricular da escola médica seria a pretensa superioridade do aluno formado em ABP sobre aquele egresso do currículo tradicional. Poucos são os trabalhos randomizados que estabelecem tal relação, os que existem não notaram diferenças marcantes entre os dois tipos de aluno. (BERKSON, 1993; KWIZERA, 2003; CARRERO, 2006).

\section{Conclusão}

Importa uma palavra de cautela na avaliação rápida e superficial do novo, em tempos de mundo globalizado, com imensos interesses econômicos em jogo diariamente. Não é possível vislumbrar a possibilidade de libertação do mercado, nem com as reflexões filosóficas de educadores do terceiro mundo, muito menos com o pensamento romântico de filósofos franceses encarregados de pensar a educação.
Tudo faz parte do mesmo jogo estratégico macroeconômico cuja única finalidade é o lucro financeiro a qualquer custo.

\section{Bibliografia}

1. ALTMANN, H. Influência do Banco Mundial no projeto educacional brasileiro. Educação e Pesquisa São Paulo, 2002; 28(1): 77-89.

2. BARROS, N.F. LOURENÇO, L.C.A. O ensino da saúde coletiva no método ABP: Experiência na faculdade de medicina de Marília.Rev Bras Educ Méd, 2006; 30(3)136-46.

3. BERKSON, L. PBL: have the expectations been met Acad Med,1993; 10:S79-S88.

4. CARRERO, E. et al.Comparison and lecture-based approach and PBL for teaching pré-anaesthetic assessment. Disponível em www.journals.cambridge. org. Acessado em 17/09/07.

5. FACULDADEDEMEDICINADAUFMG. Internato Rural. Histórico, 2007. Disponível em: www.ufmg.br/internatorural \historico. htm. Acessado em 16/09/07.

6. FANTASIA, R. Receita Americana para a reprodução da elite. Le monde diplomatique Brasil, 2004. Disponível em ww.diplo.uol.com.br/imprima1020. Acessado em 09/11/07.

7. FEUERWERKER, L. Além do discurso da mudança na educação médica.São Paulo: Hucitec, 2002.

8. GLEW, R.H. The problem with PBL in medical education. BAMBED, 2003;31(1):52-6.

9. GOLDHABER, S.Z. Harvard reverts to tradition.Science, 1973;181:1027-32.

10. JORNALELETRÔNICODOCREMESP. Entrevista com o professor Antonio Carlos Lopes: Sem preceptor não há residência, 2007; 236-4. Disponível em www. cremesp.com.br. Acesso em 18/09/07. 
11. KOMATSU, R.S. et al. Aprendizagem baseada em problemas. Im: Marcondes E Gonçalves EL.Educação Médica.São Paulo: Sarvier,1998.

12. KWIZERA, E.N. and IMPUTO, J.E. The impact of PBL/CBE in the cognitive function of UNITRA medical students, 2003. Disponível em www.cochrane.org/ colloquia/capetown.PB03.html. Acessado em 16/09/07.

13. MORAES, I.N. Reciclagem de idéias. Vascular In, 2007; 19(5): 20-22.

14. NEWFIELD, C. A crise na universidade americana, o desmonte do ideal democrático. Le monde diplomatique Brasil, 2007. Disponível em: www.diplo. uol.com.br/imprima1899. Acessado em 02/11/07.

15. PORTO, C.C. Exame Clínico.Rio de Janeiro: Guanabara Koogan, 1987.

16. RAW, I. Reformulação do ensino médico: A faculdade de medicina e a USP. Disponível em www.F: Imedicina. usp.htm. Acessado em 18/09/07.

17. SALGADO, J.A. Depoimentos ao Centro de Memória da Medicina da Faculdade de Medicina da UFMG. 1997.Disponível em: www.ufmg.br/memória. Acessado em 22/09/07.

18. SCHARTZMAN, S. Brazil: opportunity and crisis in higher education. Higher Education,1998;17(1):1-25.

19. SILVA JUNIOR, J.R. Pragmatismo e populismo na educação superior. São Paulo: Xamã,2005.

20. SMITS, P.B.A. PBL in continuing medical education: a review of controlled evaluation studies. BMJ, 2006; 324:153-55.

21. VOLTARELLI, JC. Mitos do ensino médico. Medicina Ribeirão Preto. 1998; 31(2): Editorial.

\section{Endereço para Correspondência:}

João Ozório R. Neto

joaoozorio@globo.com

Centro Universitário de Volta Redonda - UniFOA

Avenida Paulo Erlei Alves Abrantes, 1325

Três Poços - Volta Redonda - RJ

CEP: $27240-560$

Informações bibliográficas:

Conforme a NBR 6023:2002 da Associação Brasileira de Normas Técnicas (ABNT), este texto científico publicado em periódico eletrônico deve ser citado da seguinte forma: NETO, João Ozório R; CUNHA, Cleize Silveira; CUNHA, Cristiane Silveira; RODRIGUES, Adriana Novaes; TAVARES, Mauro. Aprendizagem baseada em problemas: o mito e a realidade. Cadernos UniFOA. Volta Redonda, Ano VI, n. 16, agosto 2011. Disponível em: <http://www.unifoa.edu.br/cadernos/edicao/16/79.pdf $>$ 